•编者按・

\title{
《生物多样性公约》履约新进展
}

\author{
薛达元 ${ }^{*}$
}

(中央民族大学生命与环境科学学院, 北京 100081)

\section{The latest development for implementation of the Convention on Biological Diversity}

Dayuan Xue*

School of Life and Environmental Science, Minzu University of China, Beijing 100081

《生物多样性公约》 $(\mathrm{CBD}$, 以下简称《公约》) 于1992年5月22日获得通过, 并于1993年12月29日 生效, 目前有196个缔约方。《公约》旨在促进生物 多样性的保护、可持续利用以及公平公正地分享因 利用遗传资源及相关传统知识所产生的惠益。目前 《公约》框架下通过了 3 个议定书: 《卡塔赫纳生物 安全议定书》、《名古屋-吉隆坡关于责任与赔偿的补 充议定书》和《关于遗传资源获取与惠益分享的名 古屋议定书》。《公约》还通过了一系列的工作计划、 准则、指南、倡议等规范性文件, 如 《2011-2020 生物多样性战略计划》(包括“爱知目标”) 为全球生 物多样性规划了蓝图。目前《公约》下运行的附属 机构有: 科学、技术和技艺咨询附属机构(SBSTTA, 以下简称科咨机构); 第 $8(\mathrm{j})$ (传统知识)及相关条款 工作组; 履约附属机构(SBI)。

《公约》的最高决策机制是《公约》缔约方大 会(COP)及其通过的决定。自1993年生效至今，《公 约》已经召开了13届缔约方大会, 通过了 400 多项决 定。2011年以来, 履约进入新的时期, 重点是执行 《2011-2020生物多样性战略计划》(包括“爱知目 标”), 3次缔约方大会主题也充分体现了这个精神。

COP11 (2012年10月, 印度海德拉巴)通过的决 定包括以下内容: 关于生态系统恢复、海洋和沿海 生物多样性, 传统的可持续利用方式, 关注国家以 及地方层级的履约。大会还通过了一项“截至2015 年, 将投入在生物多样性相关领域的国际资金资源 翻倍, 至少到 2020 年维持这个数字” 的中期目标, 以确保《2011-2020生物多样性战略计划》(包括“爱 知目标”)的实施。

\footnotetext{
* 通讯作者 Author for correspondence. E-mail: xuedayuan@hotmail.com
}

COP12 (2014年10月, 韩国平昌)重新确认了 COP11关于将投入到发展中国家的生物多样性保护 资金翻倍的决议。大会还通过了一揽子决定，统称 为“平昌路线图”，包括资源调动、能力建设、结合 生物多样性与减贫的科学与技术合作、监测 《2011-2020生物多样性战略计划》的履行以及实 现“爱知目标”。大会还通过了一项关于传统方式可 持续利用生物多样性的行动计划; 决定使用“土著 人民和地方社区”的术语; 在整合 《公约》与下辖议 定书的工作方式方面取得共识, 包括同期举行《公 约》和议定书会议、建立履约附属机构(SBI), 以服 务于《公约》下的所有 3 个议定书。

COP13 (2016年12月, 墨西哥坎昆)的主题是 “为人类福祉而将生物多样性保护主流化”。大会审 议了实施《2011-2020生物多样性战略计划》和实 现“爱知目标”的进展，以及履约的相关途径; 考虑 了提升实施战略计划以及 “爱知目标” 的战略行动, 包括生物多样性主流化以及将生物多样性整合到 相关部门内和跨部门的活动中。大会还审议了《公 约》与议定书相关的议题, 包括《公约》与其各议 定书之间的整合; 能力建设和技术与科学合作; 与 其他公约及国际组织的合作; 资源调动; 资金机制 和下一个两年期预算等。

科咨机构是讨论《公约》缔约方大会主题的重 要平台, 为《公约》前进方向和履约决策提供科学 技术支持。将于2017年12月11-14日在加拿大蒙特 利尔召开的科咨机构第 21 次会议将讨论 COP 14 和 COP15的会议议题, 重点为以下方面:

（1）2050年生物多样性保护愿景目标与现有相 
关目标之间的联系。保持生物多样性战略目标与行 动的连贯性和持续性对于生物多样性的保护、可持 续利用以及促进全球社会-经济可持续发展至关重 要。梳理和研究生物多样性相关战略目标与指标的 特征，寻求互补、协同增效，以及承上启下做好衔 接, 可促进生物多样性的长效保护。目前国际上与 生物多样性相关的战略目标有两个: 一是 《2011-2020生物多样性战略计划》及其“爱知目标”, “爱知目标” 共 5 类 20 项, 每项目标下都设定了具体 指标; 二是联合国《2030年可持续发展目标》，将 生物多样性的保护和可持续利用作为提高人类福 祉的重要指标。而国际社会正在考虑建立的“2050 年生物多样性保护愿景目标”, 需要与现有的战略 目标相衔接。

(2)生物多样性与人类健康。COP13提出, 就生 物多样性和人类健康议题召集机构间联络小组会 议, 由《公约》和世界卫生组织 $(\mathrm{WHO})$ 牵头, 要求 政府及相关部门增加对于生物多样性和人类健康 相互关系的关注, 在实施生物多样性战略计划以及 编制“爱知目标”后续目标时, 要将保护生物多样性 与促进人类健康联系起来。

(3)可持续的野生生物管理。随着人口的增加、 猎获技术的提高以及野生动物相关产业和贸易的 发展, 利用野生动物资源的活动日益加剧, 导致野 生生物种群急剧减少, 加速了生物多样性的丧失, 并降低了生态系统的服务功能(如种子扩散等)。科 咨机构希望在《公约》下建立一个野生生物可持续 利用管理指南, 指导各缔约方规范野生动物相关产 业和贸易。

(4)生物多样性在生产部门的主流化。主流化是 生物多样性保护的关键, 将生物多样性主流化到主 要生产部门可缓解这些部门对生物多样性的潜在 负面影响。COP13 通过了“将生物多样性主流化到农 业、林业、渔业、旅游业的决定”(第XIII/3号决定)。 在该决定的第109段中，提出在COP14上审议“将生 物多样性保护纳入到能源和采矿、基础设施、制造 和加工业及卫生部门, 使之成为这些部门的主流化 工作。”这将大大促进生产领域中生物多样性效益 和贡献最大化。

(5)评估执行《2011-2020生物多样性战略计划》
政策措施的成效。《公约》第26条要求各缔约方以 国家报告的形式评估其履约的措施及成效。COP13 第XIII/27号决定通过了第六次国家报告模板, 要求 各缔约方报告其为实现国家目标所采取的措施和 行动计划, 并对成效进行评估。第XIII/1号决定要求 各缔约方对执行 《2011-2020生物多样性战略计划》 所采取措施的成效做出评估，并通过第六次国家报 告和信息交换所机制提交关于成效评估的方法及 经验教训。此项成效评估有利于调整未来工作思路, 指导履约资源的调配, 但目前需要就系统的成效评 估手段开展相关研究。

(6)正在出现的新问题。全球范围内利用生物资 源的技术和产业迅速发展, 为生物多样性保护、可 持续利用及惠益共享带来了新的机遇和挑战。这要 求履约工作要紧跟技术革新的脚步, 做到与时俱进, 及时分析其对生物多样性保护的潜在影响。例如: 与合成生物学相关联的基因启动子技术为履约带 来新的挑战。经过基因工程处理的基因启动子可以 强化某个基因的遗传特性, 增加其在某个种群中的 普遍适应性, 确保某个特定性状能够在未来世代中 遗传下去。这种技术能够使人类对生态系统的干预 达到空前程度，同时也可能产生不可预见的负面影 响。遗传资源数字序列信息技术的使用为生物勘探 的管理和《名古屋议定书》惠益分享义务的实施带 来挑战。由于该项技术可根据数字信息人工合成所 需的生物化合物, 这就能绕开对于遗传资源的直接 实物获取, 对获取与惠益分享的界定带来困难。

COP14 将于 2018 年在埃及召开, COP 15 将于 2020 年在中国举行, 特别是COP15将审议并通过生 物多样性2050愿景战略目标和《2021-2030生物多 样性战略计划》。随着《公约》履行进入新的时期, 将 建立新的目标，并面临新的机遇和新的挑战。

本期“《生物多样性公约》履约专题”共5篇文章, 2篇是关于 《公约》下 《名古屋议定书》的履约, 包 括遗传资源获取与惠益分享国际制度进展、国家制 度的构建与重点问题讨论；1篇通过国别对比分析 了各国对“爱知目标”各项目标的关注程度; 1 篇基于 中国主办 2020 年COP15会议提出我国在生物多样 性方面的环境外交战略; 还有 1 篇是关于推动生物 多样性保护中的女性主流化。 